\title{
DA (AUSÊNCIA DE) AUTONOMIA CIENTÍFICA DA CRIMINOLOGIA
} THE (LACK OF) SCIENTIFIC AUTONOMY OF CRIMINOLOGY LA (AUSENCIA DE) AUTONOMÍA CIENTÍFICA DE LA CRIMINOLOGÍA

\author{
Nuno Caetano Lopes de Barros Poiares \\ https://orcid.org/0000-0002-9325-0206 / http://lattes.cnpq.br/8334044374958840 / nunopoiares@hotmail.com \\ ICPOL - Centro de Investigação \\ Instituto Superior de Ciências Policiais e Segurança Interna.
} Lisboa, Portugal

\author{
ANA FILIPA SANTOS \\ https://orcid.org/0000-0002-1400-0365 / http://lattes.cnpq.br/8251260819090557 / anafilipafrgsantos@gmail.com \\ Instituto Superior de Ciências Policiais e Segurança Interna. \\ Lisboa, Portugal
}

\begin{abstract}
RESUMO
O presente artigo apresenta uma síntese dos resultados de uma investigação que teve como finalidade questionar a autonomia científica da criminologia enquanto ciência interdisciplinar. Nesse sentido, desenvolveu-se um estudo de natureza qualitativa que se baseou na revisão da literatura e num inquérito por entrevista a informantes privilegiados na área em análise. Os resultados obtidos indicam que não se pode fundamentar a autonomia científica da criminologia com base no seu caráter interdisciplinar, na medida em que a criminologia só produz conhecimento, com um grau de certeza sobre o fenómeno criminal, à luz desse cruzamento de saberes. A presente investigação contribui ainda para mitigar as incertezas que a criminologia enfrenta, apresentando uma proposta de modificação ao estatuto da profissão de criminólogo em Portugal na perspetiva de se fazer justiça à sua medula interdisciplinar.
\end{abstract}

Palavras-chave: filosofia da ciência, epistemologia da criminologia, criminologia, metodologia científica, criminólogo.

\begin{abstract}
This article presents a summary of the results of an investigation that aimed to question the scientific autonomy of criminology as an interdisciplinary science. In this sense, a qualitative study was developed, which was based on a literature review and an interview interview with informants specialized in the area under analysis. The results obtained indicate that it makes no sense to justify the scientific autonomy of criminology on the basis of its interdisciplinary character, as criminology only produces knowledge, with a great degree of certainty about the criminal phenomenon, in the light of this crossing of knowledge. The present investigation also contributes to mitigate the uncertainties that criminology faces, presenting a proposal to modify the status of the profession of criminologist in Portugal in the perspective of doing justice to the interdisciplinary core of criminology.
\end{abstract}

Keywords: philosophy of science, criminology epistemology, criminology, scientific methodology, criminologist.

\section{RESUMEN}

Este artículo presenta un resumen de los resultados de una investigación que tuvo como objetivo cuestionar la autonomía científica de la criminología como ciencia interdisciplinar. En este sentido, se desarrolló un estudio cualitativo, el cual se basó en una revisión de la literatura y una entrevista a informantes especializados en el área bajo análisis. Los resultados obtenidos indican que no tiene sentido justificar la autonomía científica de la criminología en base a su carácter interdisciplinario, en que la criminología solo produce conocimiento, con un alto grado de certeza sobre el fenómeno criminal, a la luz de este cruce de saberes. La presente investigación también contribuye a mitigar las incertidumbres que enfrenta la criminología, presentando una propuesta para modificar el estatus de la profesión de criminólogo en Portugal en la perspectiva de hacer justicia a su núcleo interdisciplinario.

Palabras clave: filosofía de la ciencia, criminología, epistemología, criminología, metodología científica, criminólogo. 


\section{SUMÁRIO}

INTRODUÇAO; 1 DA FILOSOFIA DA(S) CIÊNCIA(S); 2 CRIMINOLOGIA E CIÊNCIA; 3 A PROFISSÃO DE CRIMINÓLOGO; 4 METODOLOGIA; 5. DISCUSSÃO DE RESULTADOS; CONCLUSÃO; REFERÊNCIAS.

\section{INTRODUÇÃO}

0 presente artigo tem como objetivo aprofundar o conhecimento sobre a criminologia através do questionamento da sua (eventual) autonomia científica. Pires ${ }^{1}$ evidencia a variedade de objetos de estudo da criminologia, bem como a diversidade de métodos de investigação e a proximidade que esta tem a outras disciplinas que também produzem igualmente conhecimento sobre o mesmo objeto de estudo e, dessa forma, colocam em causa a sua autonomia. Mais recentemente um estudo defende que a criminologia está dependente de outros ramos do conhecimento, realçando a sua improvável autonomia científica ${ }^{2}$. Nessa senda, considerámos cientificamente relevante clarificar se a criminologia possui autonomia e se existem motivos para que a mesma seja posta em causa, questões que a mantêm difusa e incerta ${ }^{3}$.

A criminologia surgiu da convergência de saberes como a antropologia, a sociologia, a psicologia, o direito e a biologia, não tendo conseguido afirmar-se sem estar vinculada a estes universos disciplinares. Nessa senda, a criminologia começou a ser questionada em relação às suas fronteiras, ao seu conteúdo, à sua forma de atuação e à sua relação com o campo de decisões ${ }^{4}$. Essa ausência de consenso fez com que a criminologia atravessasse uma crise de identidade quando, por exemplo, alguns autores defendem que a criminologia é uma área de especialização da sociologia que se debruça sobre o crime ${ }^{5}$. A criminologia representa uma maisvalia, sobretudo no domínio da compreensão e prevenção do crime, enquanto ciência auxiliar à governança, em particular no domínio das políticas públicas de segurança ${ }^{6}$. Acresce que o número de estudantes em criminologia tem vindo a aumentar e, recentemente, foi regulado o exercício da profissão de criminólogo ${ }^{7}$ pois, até então, a mesma não era reconhecida em Portugal, o que reforça a necessidade de se compreender o alcance da criminologia enquanto ciência e analisar a condição de criminólogo. Assim, importa analisarmos a criminologia como

\footnotetext{
1 PIRES, 1995 cit. in AGRA, Cândido e FARIA, Rita. A Criminologia: Um arquipélago interdisciplinar, 2012.

2 KAMINSKI, Dan. A improvável autonomia da criminologia: uma visada histórica e metodológica, 2017.

${ }^{3}$ AGRA, Cândido e FARIA, Rita. A Criminologia: Um arquipélago interdisciplinar, 2012.

${ }^{4}$ AGRA, Cândido e FARIA, Rita. A Criminologia: Um arquipélago interdisciplinar, 2012.

${ }^{5}$ MACHADO, Helena. Manual de Sociologia do Crime, 2008.

${ }^{6}$ POIARES, Nuno. A criminologia como ciência auxiliar da governança, 2014.

7 PORTUGAL. Lei $n .{ }^{\circ} 70 / 2019$, de 2 de setembro - regula o exercício da profissão de criminólogo. In Diário da República Eletrónico, Lisboa.
} 
ciência e como ramo do conhecimento habilitante de uma profissão, de modo a verificarmos se a regulamentação aprovada é coerente no quadro de uma ciência interdisciplinar.

\section{DA FILOSOFIA DA(S) CIÊNCIA(S)}

A legitimação da ciência teve o seu cúmulo com o Círculo de Viena (1922-1936) surgindo um movimento de desdogmatização da ciência em três vertentes fundamentais: o racionalismo crítico de Karl Popper, o convencionalismo de Kuhn e a inferência da melhor explicação de Thagard. Podemos ainda destacar uma vertente filosófica proveniente de diferentes posições teóricas, como Nietzche e Heidegger, que pensam o conhecimento a partir do devir histórico do Homem no mundo ${ }^{8}$. Quando falamos em ciência, não podemos olvidar o conceito de filosofia, pois a sua fronteira é frívola. Quando pensamos no conceito de filosofia associamos à atividade de fundamentação, de regresso, de melhor adequação às conquistas do saber e é precisamente isso que o cientista procura e é por isso que não é a filosofia que se torna ciência, mas a ciência que se torna filosofia no seu mais fundo significado ${ }^{9}$. A epistemologia refere-se à filosofia do conhecimento e à sua produção, bem como aos limites da mente humana. A epistemologia ou filosofia da ciência é o estudo das relações da ciência com o cientista e com a sociedade, em virtude de só o que tem a gramática das ciências é que pode fazer literatura ${ }^{10}$. 0 domínio da epistemologia é a análise dos métodos e conceitos do conhecimento científico, visto que não há conhecimento fora da ciência. Ou seja, a epistemologia vem questionar a veracidade das teorias científicas e é por isso que o filósofo, hoje, não pode deixar de colocar a ciência no centro da sua análise e reflexão crítica. A filosofia da ciência ou epistemologia é a disciplina que se propõe fazer o exame dos problemas relativos ao significado da ciência, à sua estrutura, ao seu papel, partindo da firme convicção de que uma acrescida consciência deles pode ser de grande utilidade, não só para o filósofo, mas também para o cientista e para qualquer pessoa de cultura $^{11}$.

A epistemologia começou a deparar-se com alguns problemas face ao aparecimento das ciências sociais, entre eles: o conceito de função, papel e o facto de não existir uma ciência, mas sim, várias ciências. A classificação das ciências interessa aos filósofos e a todos os que procuram pensar a ciência. A filosofia tem um papel crucial na classificação da ciência, uma vez

\footnotetext{
8 NEVES, José. Dicionário de Sociologia, 2002.

${ }^{9}$ SANTOS, Delfim. Filosofia e Ciência, 1952.

${ }^{10}$ BLANCHÉ, Robert. A Epistemologia, 1983.

11 GEYMONAT, Ludovico. Elementos de Filosofia da Ciência, 1985.
} 
que a esta compete tanto a fundamentação da nova ciência numa teoria crítica do saber, como a transferência de conhecimentos resultantes de uma experiência do conhecimento humano ${ }^{12}$. 0 primeiro sistema de classificação das ciências foi proposto por Aristóteles, que as dividia em três tipos: produtivas, práticas e teóricas. Esta classificação prevaleceu até o século XVIII, após a Revolução Científica que veio separar os conhecimentos em filosóficos, científicos e técnicos. A partir daí foram surgindo várias classificações com base em três critérios: o tipo de objeto estudado, o tipo de método de estudo e o tipo de resultado que é obtido. Através deste sistema surgiu a classificação que é adotada atualmente: ciências matemáticas ou lógico-matemáticas, ciências naturais, ciências humanas ou sociais, e ciências aplicadas, um processo de classificação feito de acordo com o desenvolvimento das ciências contemplando a sua complexidade e dinâmica evolutiva ${ }^{13}$.

Podemos ainda enfatizar a classificação de Bunge que dividiu a ciência em duas áreas: formais e empíricas. As formais estão associadas a variáveis existentes na nossa mente, como a matemática e a lógica; as empíricas emergem de factos e processos, entidades reais como a química e a sociologia. As ciências formais demonstram e comprovam e, por isso, podem ser consideradas como mais exatas e seguras; por outro lado as ciências empíricas baseiam-se na observação e experimentação e, assim sendo, são mais incompletas e temporárias. Por outro lado, as ciências empíricas fragmentam-se em ciências sociais e ciências naturais. Nas ciências naturais o método é analítico e bastante preciso, enquanto que as ciências sociais baseiam-se em métodos satisfatórios, pois a ciência é imperfeita na análise de variáveis subjetivas ${ }^{14}$.

0 conceito de ciência remete-nos para a mais recente fonte da verdade que difere de outras fontes (a intuição, a autoridade, a tradição e o bom senso ${ }^{15}$ ), uma vez que, através de procedimentos metodológicos, obtém evidências verificáveis e replicáveis. Todavia, a ciência defende que a verdade científica é temporária, estando sujeita a revisão e eticamente é neutra, dado que não deve estar preocupada com o discurso, com as normas, com as intencionalidades e com os valores ${ }^{16}$, mas é essencial que o conhecimento seja validado universalmente. Um dos princípios gerais para identificar o conhecimento das ciências reais é o princípio da causalidade, que nos diz que todo o processo tem uma causa e só partindo desta suspeita é que podemos obter conhecimentos na esfera das ciências reais. Por exemplo, é impossível criar e estabelecer

\footnotetext{
12 POMBO, Olga. Da classificação dos seres à classificação dos saberes, 2003.

${ }^{13}$ OLIVEIRA, Agamenon. A classificação das ciências segundo Henri Lefebvre, s.d.

14 SZCZEPANIK, Gilmar. A concepção de método científico para Mario Bunge, 2011.

${ }^{15}$ HORTON, Paul e HUNT, Chester. Sociologia, 1981, 15-16.

${ }^{16}$ AGRA, Cândido da. Elementos para uma Epistemologia da Criminologia, 2001.
} 
DA (AUSÊNCIA DE) AUTONOMIA CIENTÍFICA DA CRIMINOLOGIA

Nuno Caetano Lopes de Barros Poiares ANA FILIPA SANTOS

leis gerais como as que temos nas ciências da natureza, caso considerássemos que na natureza não reina a regularidade, a ordem e a conexão. Encontramos neste princípio uma condição da experiência possível, como defendia Kant ${ }^{17}$. A evolução filosófica dos conceitos científicos permite-nos concluir que o conhecimento científico ordena a própria filosofia, fornecendo um princípio para a classificação das filosofias e para o estudo da razão. Uma ciência realista não pode levantar problemas metafísicos pois, quando se conhecem duas propriedades de um determinado objeto, tenta-se relacioná-las e quando falamos de um conhecimento mais profundo, estamos perante uma abundância de razões interligadas ${ }^{18}$.

\section{CRIMINOLOGIA E CIÊNCIA}

A criminologia é uma área do conhecimento que tem vindo a ganhar um papel relevante na sociedade, uma vez que se dedica ao estudo do fenómeno criminal em sentido lato. Ao estudarmos a evolução da criminologia como ciência percebemos que surge associada a outras ciências, levando Cândido da Agra, um dos principais responsáveis pela institucionalização da criminologia em Portugal, a defini-la como um arquipélago interdisciplinar ${ }^{19}$. Existem outros ramos do conhecimento que também se debruçam sobre o estudo do fenómeno criminal como a biologia, o direito, a psicologia, a ética, a sociologia ou a antropologia ${ }^{20}$, verificando-se que o ofício dos criminólogos não diverge muito do trabalho de outros investigadores, que também utilizam os mesmos métodos e técnicas das ciências sociais. Atualmente têm surgido vários estudos académicos, no quadro da criminologia, que podiam ser desenvolvidos, por exemplo, num curso de sociologia, i.e. sociologia do desvio.

Por outro lado, para Faria (2014) a criminologia é uma ciência unitária e autónoma, que resulta da investigação interdisciplinar e de uma multidisciplinariedade que tem como finalidade a busca de um objeto completo e global. A criminologia possui um objeto de estudo complexo: o crime. Quando falamos de um comportamento desviante temos de considerar vários fatores internos e exógenos: as emoções, os fatores genéticos, sócio-económicos, psicológicos, psiquiátricos, entre outros. É a interação entre estes fatores que pode explicar uma determinada conduta, daí nascendo o cariz interdisciplinar da criminologia. Se a definição de criminologia fosse baseada apenas no seu objeto de estudo seria difícil conseguirmos distingui-la do direito

\footnotetext{
17 HESSEN, Johannes. Teoria do Conhecimento, 1987.

18 BACHELARD, Gaston. Os Pensadores, 1978.

${ }^{19}$ AGRA, Cândido da e FARIA, Rita. A Criminologia: Um arquipélago interdisciplinar, 2012.

20 MACHADO, Helena. Manual de Sociologia do Crime, 2008.
} 
penal. Contudo, esta destaca-se também pela sua pretensão científica e pelo seu caráter empírico. Os criminólogos fundam o seu estudo na observação e na experimentação. Desta forma, a criminologia vai além do direito penal, que desenvolve conhecimento através de um raciocínio lógico-dedutivo assente na legislação, na jurisprudência e na doutrina, enquanto a criminologia pretende conhecer a realidade, observando e experimentando. Na verdade, a institucionalização da criminologia em Portugal consolidou-se, inicialmente, a partir das Faculdades de Direito das Universidades de Coimbra, do Porto ${ }^{21}$, Lisboa e Nova, que ensinavam (e continuam a ensinar) este ramo de conhecimento no âmbito da ciência jurídica, onde pontificam, com a devida vénia, nomes como Cândido da Agra, Jorge de Figueiredo Dias, Manuel da Costa Andrade, Maria Fernanda Palma e Teresa Pizarro Beleza.

O trabalho de investigação do criminólogo não é, assim, muito diferente do trabalho de outros cientistas sociais, pois não é menosprezado nenhum método ou instrumento: tábuas de prognose, questionários, entrevistas, observação participante, exame clínico, análises estatísticas, inquéritos de vitimação, etc. No entanto, os obstáculos associados à investigação do fenómeno criminal levaram a que os criminólogos dessem relevância à descrição e à medida dos delitos, o que levou a desenvolverem os seus próprios instrumentos, como os inquéritos da gravidade das infrações, de vitimação, sobre o sentimento de insegurança e de delinquência auto-revelada ${ }^{22}$, ainda que associados a uma matriz fortemente sociológica.

0 estatuto científico da criminologia tem vindo a ser questionado devido, segundo Agra, ao amalgamento de noções e teorias contraditórias e da incapacidade para integrar a Escola Clássica e a Escola Positivista, bem como a ausência de uma teoria geral que permita sintetizar tendências divergentes. Nesse sentido propõe um regresso a Cesare Beccaria, a primeira doutrina criminológica coerente que procura juntar a prevenção no conhecimento da natureza humana e das origens do crime. Contudo, verificamos que uma das críticas à criminologia clássica é que a mesma se limitava a estudar o crime, não se importando com a reação social associada ao comportamento desviante. E esta reação social é a medula do novo paradigma e a principal responsável por colocar em questão a própria criminologia, uma vez que esta resulta de uma junção de investigação científica com a crítica, a ética e ideologia ${ }^{23}$.

A criminologia possui um objeto de estudo amplo mas tem como questão central o universo de causas precipitadoras dos comportamentos desviantes. As respostas a esta questão são diversas, são pouco consensuais e, por vezes, inconclusivas, variando de acordo com as

${ }^{21}$ Os primeiros cursos de licenciatura, mestrado e doutoramento em criminologia surgiram na FDUP.

22 CUSSON, Maurice. Criminologia, 2011.

${ }^{23}$ AGRA, Cândido da. Elementos para uma Epistemologia da Criminologia, 2001. 
épocas históricas e a perspetiva de outras ciências que também se debruçam sobre o fenómeno criminal $^{24}$. O trabalho de um criminólogo não é muito diferente do trabalho de outros investigadores das ciências sociais, todavia, a interdisciplinaridade da criminologia não significa apenas um acumular de conclusões de outras ciências como, por exemplo, a análise de aspetos propensos ao crime através da psicologia criminal ou a influência do contexto e o meio ambiente da sociologia criminal, entre outros contributos científicos. Atualmente, a criminologia é uma ciência que resulta da investigação interdisciplinar e por uma multidisciplinariedade estruturada na busca de um objetivo total ${ }^{25}$.

$\mathrm{Na}$ visão de Figueiredo Dias e Costa Andrade, a criminologia, para assumir a dignidade de ciência, terá de ser autónoma, sendo que o criminólogo deve ter liberdade para construir os seus conceitos, desde logo porque um jurista e um criminólogo falam linguagens diferentes ${ }^{26}$. Contudo, nem todos estão de acordo com esta visão, realçando a importância que a criminologia trouxe para o direito penal. "Um distanciamento do direito penal da investigação criminológica é uma atitude ignorante e arrogante. Neste sentido, Hassemer acrescenta que um juiz ao decidir tem de ter conhecimento dos problemas criminais para que a sua decisão seja certa para o caso concreto e tenha sucesso nos programas de prevenção do delito e de ressocialização do delinquente" 27 . Hermann Mannheim defende que a criminologia não é uma ciência exata porque os conteúdos e as matérias em que assentam todas as suas investigações são temporárias e, por isso, não são permanentes ${ }^{28}$. Mais recentemente, Kaminski veio demonstrar que faltam duas condições à criminologia: a autonomia disciplinar e a construção de um programa científico suscetível de se desenvolver ao longo do tempo sem intervenções externas. Afirma ainda que a criminologia é dependente, defendendo a sua improvável autonomia científica e o seu objeto de estudo como responsáveis para esta não sustentar uma posição científica ${ }^{29}$.

\section{A PROFISSÃO DE CRIMINÓLOGO}

O sociólogo Maurice Cusson entende que os criminólogos não estão sujeitos às limitações de vocabulário que pesam sobre os juristas. Alguns, adotando o olhar do sociólogo, vêem-na como um subconjunto da desviância. Outros fundam a sua análise na definição jurídica de

\footnotetext{
${ }^{24}$ MACHADO, Helena. Manual de Sociologia do Crime, 2008.

${ }^{25}$ FARIA, Miguel. Criminologia: Epanortologia, Fundamento do Direito de Punir, 2014.

${ }^{26}$ DIAS, Jorge Figueiredo e ANDRADE, Manuel Costa. Criminologia: 0 Homem Delinquente e a Sociedade Criminógena, 1997.

27 HASSEMER, 2000 cit. in VALENTE, Manuel. Teoria Geral do Direito Policial, 2016, p. 397.

${ }^{28}$ MANNHEIM, Hermann. Criminologia comparada, I, 1984.

${ }^{29}$ KAMINSKI, Dan. A improvável autonomia da criminologia: uma visada histórica e metodológica, 2017.
} 
infração. Outros ainda, insatisfeitos com o relativismo destas soluções, crêem encontrar nos factos sociais uma noção de crime fundada na razão e na justiça ${ }^{30}$. Ao interpretarmos as palavras de Cusson percebemos que, no quadro jurisdicional da profissão de criminólogo, existem vários estilos: uns que se enquadram num campo mais jurídico e outros mais sociológico. E isso deve-se ao facto de a criminologia ser uma ciência interdisciplinar que estuda o crime e analisa as causas e as formas de prevenção, intervindo na vítima e no agente do crime, mas também no contexto em que se inserem.

Em Portugal, de acordo com a Lei $n .^{\circ} 70 / 2019$, de 2 de setembro, um criminólogo está habilitado a desempenhar atividades como a análise criminológica, a elaboração e planeamento de políticas de combate à criminalidade, a conceção e execução de programas de prevenção e intervenção; diagnóstico, prognóstico e terapêutica com vista à ressocialização do agente de atos desviantes, elaboração de peritagens a arguidos e vítimas, trabalho com as Comissões de Proteção de Crianças e Jovens; elaboração de risco e de reincidência, mediação penal, investigação criminal, investigação científica, ensino da criminologia, intervenção com vítimas, elaboração de perícias nos termos previstos no Código de Processo Penal, elaboração de projetos de prevenção e tratamento da toxicodependência, integração em equipas de local de crime, coordenação de polícias de prevenção, desenvolvimento de trabalho em instituições penitenciárias e serviços de reinserção social, intervenção com ofensores ou desempenhar funções no âmbito da criminalidade económica e financeira.

A criminologia, como campo do conhecimento institucionalizado, é uma área recente, mas o mesmo não se pode dizer relativamente ao exercício de compreensão do crime ao longo da história humana. Ainda assim, a profissão de criminólogo continua a não ter o mesmo destaque que outras profissões da área da justiça criminal, todavia ela representa uma maisvalia para a prevenção e estudo do crime. A principal tarefa do criminólogo é estudar a prevenção de comportamentos desviantes e reduzir a reincidência. Os criminólogos analisam estatísticas para identificar padrões, assim como os tipos legais de crime, os dados demográficos e os locais. Podem ainda entrevistar criminosos com o objetivo de entender as suas motivações e atitudes; e cooperar com líderes comunitários e políticos para desenvolver políticas para ajudar a reduzir o crime e garantir a ressocialização dos criminosos ${ }^{31}$.

A profissão de criminólogo em Portugal foi reconhecida apenas em 2019. Todavia, em 2010, a licenciatura em criminologia da Faculdade de Direito da Universidade do Porto (FDUP) já

\footnotetext{
30 CUSSON, Maurice. Criminologia, 2011, p. 14.

31 https: / / www.thebalancecareers.com/criminologist-career-profile-974483, Acesso em: 22 set. 2019.
} 
era um dos cursos mais procurados no ensino superior público. A FDUP abriu 50 vagas e candidataram-se 302 candidatos. De acordo com Simas Santos, diretor da licenciatura no Instituto Superior da Maia (ISMAI), nos EUA a criminologia é bastante utilizada como serviço de consultoria, sendo que alguns advogados recorrem a criminologistas/criminólogos para o auxílio na resolução de casos criminais. Para além disso, Simas revela que a criminologia também pode intervir no urbanismo (bairros sociais ou grandes bairros). Para além destes apontamentos em relação à profissão de criminólogo, relembra que, quando começou os seus estudos, não existia psicologia, mas apenas filosofia, e foi o aparecimento desse curso que fez com que começassem a surgir novas saídas profissionais. Outro nome relevante na área da criminologia e da medicina legal, o Professor Pinto da Costa, defende que o mercado português necessita de criminologistas referindo que a instabilidade emocional e as dificuldades financeiras são propícias ao crime. Contudo, o mercado de trabalho para estes profissionais está dependente do Estado e da iniciativa privada ${ }^{32}$. Atualmente, a profissão de criminólogo está regulamentada através da Lei n. ${ }^{\circ} 70 / 2019$, de 2 de setembro, sendo que o projeto de lei foi levado à Assembleia da República no dia 4 de janeiro de 2019. De acordo com a Associação Portuguesa de Criminologia (APC) existem cerca de 1.100 criminólogos formados em Portugal e apenas os licenciados em criminologia estão aptos legalmente para o exercício da profissão. Atualmente, a licenciatura em criminologia pode ser obtida na Faculdade de Direito da Universidade do Porto, na Universidade Fernando Pessoa, no Instituto Superior da Maia, na Universidade Lusíada do Porto e na Universidade do Minho $^{33}$. Ainda de acordo com a APC, os criminólogos estão aptos para exercer a sua profissão em órgãos de polícia criminal, no ministério da justiça, em tribunais, gabinetes de mediação, institutos penitenciários, serviços de reinserção social, centros educativos para menores delinquentes, serviços de inspeção das atividades económicas, comissões de proteção de crianças e jovens, centros de acolhimento e assistência a vítimas, centros e projetos de prevenção e tratamento da toxicodependência, autarquias, empresas de segurança privada, projetos de investigação científica e institutos de ensino de criminologia ${ }^{34}$. Diarmaid Harkin é professor de criminologia na Universidade de Deakin, Austrália, e tem focado o seu estudo para as políticas de policiamento comunitário na Escócia. Na sua opinião, os criminólogos vêm de diversos campos e são definidos mais pelo assunto e não propriamente pela especialização ou competência necessária. Para ele, a criminologia representa um confluente de

\footnotetext{
32 https://jpn.up.pt/2012/03/15/criminologia-nova-area-novos-profissionais, Acesso em: 22 set. 2019.

33 Atualmente encontra-se a decorrer o processo de acreditação, junto da A3ES, de um novo curso de licenciatura em Criminologia da Faculdade de Direito da Universidade Lusófona de Lisboa.

34 http://apcriminologia.com/pt/, Acesso em: 22 set. 2019.
} 
diferentes domínios, ou seja, uma combinação de disciplinas como a sociologia, o direito e a ciência política. Por isso, os criminólogos são inerentemente interdisciplinares e têm um conjunto de habilidades. Refere ainda que a criminologia pode preparar os estudantes para diferentes caminhos: empregos associados à aplicação da lei, serviços de apoio à vítima, reabilitação e reintegração do agressor, mas também oportunidades na área do planeamento e estratégia de políticas de forma a tornar as comunidades mais seguras ${ }^{35}$. Por outro lado, no sítio "Criminal Justice USA", é defendido que a criminologia é uma área da sociologia que se foca no estudo do crime, nas suas causas e efeitos, bem como no seu impacto social. As responsabilidades de um criminólogo envolvem, por isso, a análise de dados para perceber o porquê do crime ter sido cometido e procurar formas de prevenir e impedir comportamentos criminosos no futuro. Assim, o criminólogo centra a maior parte da sua atividade em laboratório ou escritório para recolher e registar os dados que serão usados em investigações criminais e na reflexão sobre políticas públicas. As oportunidades de emprego para estes profissionais encontram-se em agências governamentais federais e estaduais, policiais, empresas privadas e nos departamentos de pesquisa de faculdades e universidades. Todavia, é necessário ter em consideração as qualificações mínimas exigidas para a posição de criminólogo ou criminologista. De acordo com o The Princeton Review, o requisito educacional para cargos de nível básico de criminologia é, pelo menos, um diploma de Bacharel, contudo alguns empregadores exigem cursos de pós-graduação. A maioria dos criminologistas é formado em psicologia ou sociologia, mas geralmente com ênfase em ciências criminais e, muitas das vezes, as escolas oferecem programas de graduação em criminologia online e no campus. Alguns empregadores exigem experiência de trabalho, geralmente sob a supervisão de um criminólogo mais experiente. Para além disso, os requisitos variam consoante os Estados: alguns não exigem quaisquer requisitos e alguns incluem padrões educacionais e profissionais mínimos ${ }^{36}$.

\section{METODOLOGIA}

O objeto de estudo da presente investigação qualitativa é a autonomia científica da criminologia, uma vez que é considerada, por alguns autores, como uma "não-ciência", na medida em que a criminologia foca-se numa diversidade de objetos de estudo, de métodos e encontra-se dependente de outras disciplinas ${ }^{37}$. Assim, para que a criminologia não continue a

\footnotetext{
${ }^{35} \mathrm{https}$ // / this.deakin.edu.au/career/whats-it-really-like-to-be-a-criminologist. Acesso em: 22 set. 2019.

${ }^{36}$ https: / /www.criminaljusticeusa.com/criminologist/, acesso em: 22 set. 2019.

${ }^{37}$ KAMINSKI, Dan. A improvável autonomia da criminologia: uma visada histórica e metodológica, 2017.
} 
ser considerada difusa e incerta ${ }^{38}$ é fundamental clarificar a sua autonomia científica e, em paralelo, os elementos que estruturam a jurisdição profisisonal de um criminólogo.

$\mathrm{Na}$ investigação qualitativa a fonte direta dos dados é o ambiente natural e o investigador é o principal responsável na recolha de dados, os dados que o investigador recolhe são de carácter descritivo, os investigadores que utilizam metodologia qualitativas interessam-se mais pelo processo do que pelos resultados, a análise dos dados é feita de forma indutiva e o investigador tem vontade em tentar compreender o significado que os participantes atribuem às suas experiências ${ }^{39}$. Assim, de acordo com a problemática em análise, o tipo de pesquisa que mais se adequa é a qualitativa de caráter exploratório. Para esse efeito recorremos à pesquisa bibliográfica, mas também à pesquisa de campo, optando pela aplicação de um inquérito por entrevista. As entrevistas permitem-nos ter uma compreensão mais detalhada acerca do assunto pesquisado ${ }^{40}$ e é a mais flexível de todas as técnicas de recolha de dados de que dispõem as ciências sociais ${ }^{41}$.

Para a preparação e execução das entrevistas começamos por elaborar um guião de acordo com os objetivos da investigação, focando duas questões em particular: a criminologia enquanto ciência e a análise da profissão de criminólogo. Nesse sentido, considerámos essencial entrevistar três informantes privilegiados provenientes de áreas diferentes para complementar e consolidar os resultados finais: um informante da área da filosofia que nos pudesse dar a sua visão em relação à epistemologia ou filosofia da ciência; um profissional da área da criminologia, com a finalidade de entender a sua opinião em relação à criminologia e aos estatutos da profissão de criminólogo e, por fim, um profissional com vasta experiência na área da criminologia, mas com uma formação diferente, para que possamos perceber qual é a sua perspetiva em relação à criminologia e à profissão. Optámos por entrevistar Henrique Leitão (investigador principal no Centro Interuniversitário de História da Ciência e da Tecnologia e presidente do Departamento de História e Filosofia da Ciência da Faculdade de Ciências da Universidade de Lisboa), Vítor Silva (presidente da Associação Portuguesa de Criminologia) e José Pinto da Costa (médico e professor catedrático jubilado de Medicina Legal e Psicologia Forense no Instituto de Ciências Biomédicas de Abel Salazar da Universidade do Porto).

\footnotetext{
${ }^{38}$ AGRA, Cândido da e FARIA, Rita. A Criminologia: Um arquipélago interdisciplinar, 2012.

39 BOGDAN, Robert e BIKLEN, Sari. Investigação Qualitativa em Educação, 1994.

40 GASKELL, George. Entrevistas individuais e grupais, 2002.

${ }^{41}$ GIL, António Carlos. Métodos e técnicas de pesquisa social, 1999.
} 


\section{DISCUSSÃO DE RESULTADOS}

No decurso do presente estudo e à luz da entrevista com Henrique Leitão verificamos que existe uma dificuldade em definir ciência, dilema controverso presente até ao século XX entre os filósofos. Todavia, para mitigar essa controvérsia, surgiram critérios de demarcação. Henrique Leitão defendeu que é importante perceber o alcance do conceito de ciência pois, ciências naturais não significam o mesmo que ciências sociais e, para o informante, estas últimas podem ser consideradas como ciência dentro do seu espetro, uma vez que conseguem alcançar certos graus de certeza, ainda que parcelar e limitada. Considera que é isto que surge posterior à reclamação das ciências sociais, ou seja, são disciplinas que não pretendem ser como as ciências naturais, mas querem demonstrar que produzem conhecimento com um elevado grau de certeza. Mas não existem verdades absolutas pois toda a verdade científica é provisória, estando sujeita à neutralidade e à revisão de novas evidências ${ }^{42}$.

Verificámos que existe alguma resistência em definir a criminologia como ciência, com base na sua dependência relativamente a outras disciplinas, uma vez que, para produzir conhecimento, necessita de recorrer a métodos de disciplinas como a sociologia, o direito, a psicologia, a antropologia ou a biologia. Assim, foi fundamental perceber se o facto de uma disciplina ser metodologicamente dependente pode retirar-lhe o estatuto de ciência, concluindo que quase todas as ciências apresentam um grau variável de dependência. Henrique Leitão dános o exemplo da Química que está profundamente interligada à Matemática e à Física e que ninguém questiona a sua qualidade de ciência. Desta forma considera que uma ciência pode estar dependente pois representa um compósito de saberes inter-relacionados. Menciona ainda que, quando usamos a palavra ciência na criminologia, é com o fundamento de evidenciar a possibilidade de adquirirmos afirmações com um grau elevado de certeza, pois a criminologia recolhe métodos provenientes de outros ramos do conhecimento, mas depois confere-lhes alguma unicidade, o que permite atingir certezas elevadas sobre algumas afirmações, ou seja, uma possibilidade de adquirir conhecimento certo. Por outro lado, para Vítor Silva, a interdisciplinaridade da criminologia faz parte da sua natureza científica e é o facto de se apoderar de diferentes métodos e fontes que permite que a criminologia produza um conhecimento mais profundo, que em nada reduz a sua autonomia, pois a ciência deve ser ativa na procura de conhecimento, considerando que a criminologia tem um método próprio, 0 método compósito. Consideramos que Vítor Silva refere-se, como Henrique Leitão, a um método

42 HORTON, Paul e HUNT, Chester. Sociologia, 1981. 
que advém de outros métodos, transformando-os na sua própria metodologia. Também para Pinto da Costa, a interdisciplinaridade representa uma vantagem e não faz sentido a visão de uma ciência isolada, contudo considera que a criminologia não tem um método específico, pois os métodos que utiliza são provenientes de outras disciplinas. É importante termos em conta estas três opiniões, pois representam abordagens distintas, o que nos permite ter uma visão mais ampliada e holística. Como síntese podemos concluir que a interdisciplinaridade e a dependência da criminologia não representam um motivo para deixarmos de a identificar como ciência. Relativamente ao método consideramos que a opinião de Henrique Leitão é a mais coerente e que, de certo modo, engloba as outras opiniões, pois considera que a criminologia utiliza, analisa e funde os métodos de outras disciplinas, conferindo-lhes unicidade na análise do fenómeno criminal.

Outro resultado relevante refere-se à análise da profissão de criminólogo, uma vez que a mesma padece da mesma controvérsia que a criminologia, pois não se pode esperar uma definição objetiva quando provém de um campo do conhecimento que suscita diversas inquietações. De acordo com Vítor Silva, para o exercício da profissão de criminólogo em Portugal, à luz da legislação em vigor, é unicamente necessário a titularidade de um curso de licenciatura em criminologia pois, na sua opinião, só assim o indivíduo detém conhecimentos profundos e exatos de criminologia. 0 presidente da APC entende que não existe a possibilidade de um indivíduo com uma licenciatura diferente, mas com formação pós-graduada em criminologia, intitular-se como criminólogo, uma vez que essas formações representam apenas especializações. Pinto da Costa é da mesma opinião em relação aos requisitos e considera que é necessária uma licenciatura em criminologia, todavia entende que tem de existir um campo prático, ou seja, uma atividade afirmativa que leve os criminólogos a atuar na sociedade. Contudo, considera que um indivíduo que possua uma licenciatura em outra área e um mestrado ou doutoramento em criminologia deve poder atuar como criminólogo, pois considera que, não havendo uma Ordem dos Criminólogos, nem um Sindicato e se um indivíduo atuar na prática como tal, deve ser intitulado de criminólogo.

Nessa senda é importante analisar a relevância da licenciatura em criminologia para o exercício do mandato profissional, tendo em conta que só em 2019 é que a profissão de criminólogo foi reconhecida. Para José Pinto da Costa a licenciatura em criminologia não é vantajosa, pois o emprego é muito precário, considerando que o Governo é um dos principais responsáveis, por não the conferir a devida importância. Vítor Silva considera que a principal vantagem da licenciatura em criminologia é o conhecimento relacionado com o fenómeno 
criminal que apenas esta licenciatura proporciona. Afirma que existem muitas funções que um criminólogo pode exercer na sociedade e que estão também presentes na legislação referente à mesma, sendo que já existem várias instituições públicas e privadas que têm vindo a reconhecer a importância de integrar equipas de criminólogos.

Em alguns países, como verificámos anteriormente, os criminólogos provêm de diversos campos e são definidos pela área de intervenção e não propriamente pela especialização necessária, uma vez que os criminólogos são inerentemente interdisciplinares, sendo que a maioria dos criminólogos é formado em sociologia ou psicologia, mas geralmente com ênfase e especialização nas ciências criminais. Consideramos que a visão de Pinto da Costa vai ao encontro desta realidade, apesar de o mesmo mencionar a licenciatura de criminologia como um dos requisitos para a denominação de criminólogo. Mas, quando questionado em relação à possibilidade de um licenciado em outra área, com uma especialização em criminologia poder intitular-se como criminólogo, entende que devia ser intitulado como tal, uma vez que, na prática, atua como criminólogo. Partilhamos a mesma visão pois a criminologia é interdisciplinar e, por isso, o mandato de criminólogo também deve herdar essa genética.

\section{CONCLUSÃO}

A criminologia não consegue produzir conhecimento sem a invocação de outras ciências, pois só consegue produzir resultados através dessa convergência. 0 estudo do delinquente, por exemplo, só é possível através do conhecimento que a psicologia e a psiquiatria the oferecem. Assim como o estudo da legislação, de forma a adequá-la às necessidades, também está dependente do direito; e o estudo do contexto social surge dependente da sociologia. No nosso entendimento esta dependência interdisciplinar não diminui a sua relevância, uma vez que permite produzir conhecimento mais aprofundado acerca do tema, pois não está restringida apenas a uma perspetiva disciplinar. A sua existência reside na triangulação, no olhar rashomoniano. Ou seja, não se baseia apenas nos dados estatísticos do crime, ou apenas no perfil da personalidade dos delinquentes, ou somente no quadro legal adequado, nem apenas no contexto social. Simas referiu que a psicologia só começou a ganhar soluções no mercado após a criação da respetiva licenciatura, tendo a criminologia seguido o mesmo rumo ao conseguir que a profissão de criminólogo fosse reconhecida em Portugal. Contudo, entendemos que devem ser 
tomadas algumas cautelas em relação ao estatuto de criminólogo pois consideramos que, sendo a criminologia uma ciência interdisciplinar que enriquece e depende de outras ciências, não é coerente que a profissão se restrinja apenas a licenciados em criminologia. Em Portugal a institucionalização da sociologia, por exemplo, desenvolveuse a partir dos estudos doutorais desenvolvidos por cientistas provenientes de diversos domínios científicos, como Boaventura de Sousa Santos, professor catedrático jubilado da Faculdade de Economia da Universidade de Coimbra que, sendo licenciado em direito, é internacionalmente reconhecido como sociólogo, área onde se doutorou.

Pensamos, assim, nos doutores e mestres em criminologia que iniciaram os seus estudos em outras áreas como o direito, a psicologia ou a sociologia e se vieram fundar na criminologia. E também os sociólogos, antropólogos, psicólogos e os juristas criminais que devem ser reconhecidos à luz da profissão de criminólogo. Entendemos também que limitar o estatuto de criminólogo a licenciados em criminologia é reduzir a sua essência, enquanto ciência interdisciplinar. Em outros países, o mandato de criminólogo não é balizado por uma única licenciatura, pois a criminologia é um espaço de confluência de diferentes áreas do saber e, por isso, os criminólogos são interdisciplinares por natureza e têm diversas competências. Acresce que, nessas realidades, a maioria dos criminólogos é formada em psicologia e sociologia, mas com uma especialização em ciências criminais. Consideramos que esta é a visão mais correta em relação à configuração da profissão de criminólogo, pois não faz sentido assumirmos a interdisciplinaridade da criminologia e não o fazermos em relação à profissão, na medida em que estamos a contrariar a sua natureza.

Vítor Silva, presidente da Associação Portuguesa de Criminologia, considera que apenas a licenciatura em criminologia permite um indivíduo ser intitulado de criminólogo, visão que foi aprovada legalmente. Todavia, entendemos que esta ideia apresenta uma contradição. A defesa da criminologia como uma ciência interdisciplinar, a sua dependência e o elevado conhecimento que a mesma proporciona em diversas áreas devido ao seu caráter interdisciplinar, sem, contudo, assumir a interdisciplinaridade da profissão representa uma incoerência. Assim como também não entendemos coerente a comparação deste requisito a outras disciplinas que também 
apresentam a mesma exigência formal, pois têm um método próprio e conseguem produzir conhecimento de forma autónoma. A criminologia produz conhecimento profundo porque depende de outras ciências e a profissão à qual corresponde também herda essa interdisciplinaridade. Por isso, somos da opinião que um indivíduo que, por exemplo, seja licenciado em psicologia, mas tenha uma especialização em criminologia tem o direito de ser intitulado como criminólogo, uma vez que está a produzir conhecimento para a criminologia. Nesse sentido, consideramos que importa rever esta contradição na regulamentação da profissão de criminólogo. Reconhecemos que foi importante o reconhecimento da profissão e que foi um passo relevante para a sua legitimação na sociedade. Contudo, entendemos que não foi o suficiente para que a criminologia ganhasse uma posição mais visível e consolidada na comunidade científica.

O presente estudo surgiu da necessidade de libertar a criminologia de um rótulo de incertezas pois a mesma depende de outras áreas do saber para produzir conhecimento, sendo que essas mesmas áreas também produzem conhecimento sobre o fenómeno criminal. Nesse sentido, considerámos relevante abordar a epistemologia da criminologia, uma vez que, para conseguirmos perceber se a criminologia pode ser considerada uma ciência é necessário ir à sua génese. Ao estudarmos o conceito de ciência verificamos que a mesma é bastante ambígua, uma vez que existem várias interpretações e significados pois, quando se fala em ciência, é importante perceber o seu sentido, ou seja, falar em ciências naturais e em ciências sociais não é a mesma coisa. Acresce que discutir a autonomia das ciências sociais é ilógico pois, quando se fala em ciências socias, é necessário ter em consideração que se pretende reclamar, não a exatidão e a precisão, mas sim a capacidade de adquirir conhecimento com um elevado grau de certeza. A interdisciplinaridade e a dependência não questionam a dignidade de ciência de uma determinada disciplina e, nesse sentido, podemos concluir que a criminologia é uma ciência que produz conhecimento com grande grau de certeza devido à sua dependência, uma vez que é através do cruzamento de diversas áreas do saber que consegue estudar o fenómeno criminal de forma holística. Nessa linha de pensamento percebemos que o coração da criminologia é o seu caráter interdisciplinar e é essa característica que a mantém ativa no mundo da ciência. Todavia o estatuto da profissão 
DA (AUSÊNCIA DE) AUTONOMIA CIENTÍFICA DA CRIMINOLOGIA

de criminólogo limita a mesma à licenciatura em criminologia, o que representa uma incongruência. Para finalizar, queremos mencionar alguns constrangimentos que sentimos ao longo da nossa investigação, entre eles, a escassa literatura no âmbito da presente abordagem. Com o nosso estudo pretendemos evidenciar o papel relevante do criminólogo e, por isso, consideramos que seria importante implementar a criminologia de forma mais precoce no nosso ensino, uma vez que esta área está cada vez mais presente no nosso dia-a-dia e o desconhecimento não contribui para a prevenção. Muitas são as notícias sobre violência e abusos em que as próprias vítimas e a família não conseguem identificar as ações e os atos como tal, uma vez que o contexto em que estão incluídos não lhes permite percecionar a realidade. Por isso, defendemos que é fundamental apostar na prevenção do crime e na identificação de comportamentos desviantes, através da integração da criminologia no currículo do ensino secundário. Propomos ainda que o estatuto de criminólogo seja repensado tendo em conta a sua essência interdisciplinar. Para o futuro seria igualmente interessante perceber até que ponto não seria possível a criação de áreas de especialização na profissão de criminólogo, à semelhança do que ocorre na área da sociologia, do direito e da psicologia.

Terminamos pela mão de um dos principais responsáveis pela institucionalização da criminologia em Portugal, o professor catedrático de criminologia, com formação em psicologia, Cândido da Agra: "existe abundante investigação empírica sobre o delinquente, o crime, a criminalidade, mais recentemente sobre a vítima e o sistema de justiça. Rara é, porém, a investigação que sistematiza criticamente a evidenciação empírica e teórica da criminologia e, quando existe, a fundamentação epistemológica é praticamente nula" ${ }^{43}$. Com esta afirmação pretendemos salientar a importância de analisar as bases científicas da criminologia através da fundamentação epistemológica pois as fundamentações através do uso da epistemologia são quase nulas.

\footnotetext{
${ }^{43}$ AGRA, Cândido da. Elementos para uma Epistemologia da Criminologia, 2001, p. 63.
} 


\section{REFERÊNCIAS}

AGRA, Cândido da e FARIA, Rita. A Criminologia: um arquipélago interdisciplinar. Porto: Universidade do Porto. 2012.

AGRA, Cândido da. Elementos para uma Epistemologia da Criminologia. Estudos em comemoração dos cinco anos da Faculdade de Direito da Universidade do Porto. Coimbra: Coimbra Editora, 2001.

BACHELARD, Gaston. Os Pensadores. Brasil: Victor Civita, 1978.

BLANCHÉ, Robert. A Epistemologia. Lisboa: Editorial Presença, 1983.

BOGDAN, Robert e BIKLEN, Sari. Investigação Qualitativa em Educação - uma introdução à teoria e aos métodos. Porto: Porto Editora, 1994.

CUSSON, Maurice. Criminologia, 3. ${ }^{a}$ edição. Alfragide: Casa das letras, 2011.

DIAS, Jorge de Figueiredo e ANDRADE, Manuel da Costa. Criminologia: 0 Homem Delinquente e a Sociedade Criminógena, 2. ${ }^{\mathrm{a}}$ reimpressão, Coimbra: Coimbra Editora, 1997.

FARIA, Miguel. Criminologia: Epanortologia, Fundamento do Direito de Punir. Lisboa: ICPOL ISCPSI, 2014.

GASKELL, George. Entrevistas individuais e grupais. Petrópolis: Vozes, 2002.

GEYMONAT, Ludovico. Elementos de Filosofia da Ciência. Lisboa: Trajectos, 1985.

GIL, António Carlos. Métodos e técnicas de pesquisa social. ( $5^{\mathrm{a} e d}$ ). São Paulo: Atlas, 1999.

HESSEN, Johannes. Teoria do Conhecimento. $8 .^{a}$ ed. Trad. António Correia. Coimbra: Arménio Amado Editora, 1987.

HORTON, Paul e HUNT, Chester. Sociologia. Brasil: McGraw- Hill, 1981.

MACHADO, Helena. Manual de Sociologia do Crime. Porto: Edições Afrontamento, 2008.

MANNHEIM, Hermann. Criminologia comparada, I, tradução de Manuel da Costa Andrade e José Faria Costa. Lisboa: Fundação Calouste Gulbenkian, 1984.

NEVES, José. Dicionário de Sociologia. Porto: Porto Editora, 2002.

OLIVEIRA, Agamenon. A classificação das ciências segundo Henri Lefebvre. Escola Politécnica da UFRJ, s/d.

POIARES, Nuno. A criminologia como ciência auxiliar da governança. Revista Científica do ISCTAC, v. 1, n. ${ }^{\circ}$ 2, dez. 2014. ISSN 2519-7207, 2014. Disponível em:

<http://isctac.org/revista/index.php/revistacientifica/article/view/13>. Acesso em: 30 out. 2017. 
POMBO, Olga. Da classificação dos seres à classificação dos saberes, 2003. Disponível em https://www.researchgate.net/publication/255612117. Acesso em: 29 set. 2018.

PORTUGAL. Lei n. ${ }^{\circ} 70 / 2019$, de 2 de setembro - regula o exercício da profissão de criminólogo. In Diário da República Eletrónico, Lisboa. Disponível em https://dre.pt/home/-

/dre/124346821/details/maximized. Acesso em: 30 out. 2017.

KAMINSKI, Dan. A improvável autonomia da criminologia: uma visada histórica e metodológica.

Passagens. Revista Internacional de História Política e Cultura Jurídica Rio de Janeiro: vol. 9, n. ${ }^{\circ}$ 2, maio-agosto, 2017, pp. 170-190, 2017.

SANTOS, Delfim. Filosofia e Ciência. Separata, Ciência, Revista dos Estudantes da Faculdade de Ciências de Lisboa. Ano III, n. ${ }^{\circ}$ 6, pp. 22-25, 1952.

SZCZEPANIK, Gilmar. A concepção de método científico para Mario Bunge. Revista Guairacá, pp. 9-30, n. ${ }^{\circ}$ 27, ISSN 0103-250X, 2011.

VALENTE, Manuel. Teoria Geral do Direito Policial. Coimbra: Almedina, 2016.

\section{WEBGRAFIA:}

https://www.thebalancecareers.com/criminologist-career-profile-974483, Acesso em: 22 set. 2019.

https://jpn.up.pt/2012/03/15/criminologia-nova-area-novos-profissionais, Acesso em: 22 set. 2019.

http://apcriminologia.com/pt/, Acesso em: 22 set. 2019.

https: //this.deakin.edu.au/career/whats-it-really-like-to-be-a-criminologist, Acesso em: 22 set. 2019.

https://www.criminaljusticeusa.com/criminologist/, Acesso em: 22 set. 2019.

$$
\text { Artigo convidado }
$$

\section{COMO FAZER REFERÊNCIA AO ARTIGO (ABNT):}

POIARES, Nuno Caetano Lopes de Barros; SANTOS, Ana Filipa. Da (ausência de) autonomia científica da criminologia. Revista Eletrônica do Curso de Direito da UFSM, Santa Maria, RS, v. 15, n. 2, e63837, maio/ago. 2020. ISSN 1981-3694. DOI: http://dx.doi.org/10.5902/1981369463837. Disponível em: https://periodicos.ufsm.br/revistadireito/article/view/63837 Acesso em: dia mês. ano.

Direitos autorais 2020 Revista Eletrônica do Curso de Direito da UFSM

Editores responsáveis: Rafael Santos de Oliveira e Angela Araujo da Silveira Espindola

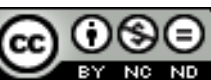

Esta obra está licenciada com uma Licença Creative Commons Atribuição-NãoComercial-SemDerivações 4.0 Internacional. 
ISSN 1981-3694

(DOI): $10.5902 / 1981369463837$

\section{SOBRE OS AUTORES}

Nuno Caetano Lopes de BarRos Poiares

Graduado em Direito e em Ciências Policiais. Mestre em Sociologia. Curso de especialização do Mestrado em Direito Penal (FDUL). Especialista em Direito Penal (com provas públicas). Doutor em Sociologia (Direito, Crime e Segurança). Investigador Integrado do ICPOL-ISCPSI. Professor do Instituto Superior de Ciências Policiais e Segurança Interna, do Instiuto Politécnico de Beja e da Faculdade de Direito da Lusófona de Lisboa (Portugal). Diretor do Departamento Científico de Ciências Policiais e Coordenador do Mestrado em Ciências Policiais do ISCPSI. Oficial Superior da Polícia de Segurança Pública (Portugal). Autor de vários livros, capítulos de livros e artigos em revistas científicas indexadas.

\section{ANA FILIPA SANTOS CORREIO}

Licenciada em Psicologia, mestre e pós-graduada em Criminologia e Investigação Criminal (17 valores). Curso de "Crianças e Jovens vítimas de crime e violência" (17 valores) e curso intensivo de Criminologia (17 valores). Experiência como Consultora de Recursos Humanos em empresas de vários sectores e curso de Gestão de Recursos Humanos concluído com 18 valores. 